\title{
Risk of medication overuse headache across classes of treatments for acute migraine
}

\author{
Kristian Thorlund ${ }^{1,2^{*}}$, Christina Sun-Edelstein ${ }^{3}$, Eric Druyts ${ }^{2,4}$, Steve Kanters ${ }^{2,5}$, Shanil Ebrahim ${ }^{1}$, Rahul Bhambri ${ }^{6}$, \\ Elodie Ramos ${ }^{6}$, Edward J. Mills $^{1,2}$, Michel Lanteri-Minet ${ }^{7,9}$ and Stewart Tepper ${ }^{8}$
}

\begin{abstract}
Background: The most commonly prescribed medications used to treat migraine acutely are single analgesics, ergots, opioids, and triptans. Due to varying mechanisms of action across drug classes, there is reason to believe that some classes may be less likely than others to elicit Medication Overuse Headache (MOH) than others. We therefore aimed to determine whether certain classes of acute migraine drugs are more likely to elicit $\mathrm{MOH}$ than others.
\end{abstract}

Methods: A comprehensive systematic literature was conducted to identify studies of varying designs that reported on $\mathrm{MOH}$ within the considered treatment classes. Only studies that reported $\mathrm{MOH}$ according to the International Classification of Headache Disorders (ICHD) were considered. Since no causal comparative design studies were identified; data from prevalence studies and surveys were retrieved. Prevalence-based relative risks between treatment classes were calculated by integrating both medication overuse and medication use from published studies. For each pair wise comparison, pooled relative risks were calculated as the inverse variance weighted average.

Results: A total of 29 studies informed the relative risk between treatment classes, all of which reported country-specific data. Five studies reported country-specific medication use data. For triptans versus analgesics the study relative risks generally favored triptans. The pooled relative risk was 0.65 (i.e., relative risk reduction of $35 \%$ ). For ergots versus analgesics, a similar trend was observed in favor of ergots with a relative risk of 0.41 . For triptans versus ergots, the direction of effect was mixed, and the pooled relative risk was 1.07. Both triptans and ergots appeared favorable when compared to opioids, with pooled relative risks of 0.35 and 0.76 , respectively. However, the evidence was limited for these comparisons. Analgesics and opioids also appeared to yield similar risk of $\mathrm{MOH}$ (pooled relative risk 1.09).

Conclusion: Our study suggests that in patients receiving acute migraine treatment, analgesics and opioids are associated with a higher risk of developing $\mathrm{MOH}$ compared with other treatments. These findings provide incentive for better monitoring of use of analgesics and opioids for treating acute migraine, and suggest possible clinical preference for use of so-called "migraine-specific" treatments, that is, triptans and ergots.

\section{Background}

Medication-overuse headache $(\mathrm{MOH})$ is caused by overuse of medications for migraines or other pain disorders. According to the International Classification of Headache Disorders, $3^{\text {rd }}$ Edition, Beta (ICHD-3), $\mathrm{MOH}$ is defined as headache occurring on 15 or more days per month

\footnotetext{
* Correspondence: kthorlund@redwoodoutcomes.com

${ }^{1}$ Department of Clinical Epidemiology \& Biostatistics, McMaster University, Hamilton, ON, Canada

${ }^{2}$ Redwood Outcomes, 302-1505 2nd Ave. West, Vancouver, BC, Canada Full list of author information is available at the end of the article
}

developing as a consequence of regular overuse of acute or symptomatic headache medication (on 10 or more, or 15 or more days per month, depending on the medication) for more than 3 months [1].

$\mathrm{MOH}$ manifests as increased frequency and intensity of headaches or migraine attacks and enhanced sensitivity to stimuli that elicit these episodes [2] Although the mechanisms underlying $\mathrm{MOH}$ are not fully elucidated, it is hypothesized that repeated medication use could elicit increased headache attacks as a consequence of neuronal plasticity that may increase responsiveness to triggers. The 
prevalence of $\mathrm{MOH}$ is $1-2 \%$ in the general population worldwide, and because of the estimated socio-economic cost, it is likely to be the most costly neurological disorder known [3-6].

Commonly prescribed medications for migraines may include analgesics, ergots, opioids, and triptans. Due to varying mechanisms of action across drug classes, there is reason to believe that some classes may be less likely than others to elicit $\mathrm{MOH}$. Because of the estimated socio-economic burden of $\mathrm{MOH}$, it is therefore important to establish which drug class generally is least likely to elicit $\mathrm{MOH}$.

The aim of this study was therefore to determine whether certain classes of acute migraine drugs are more likely to elicit $\mathrm{MOH}$ than others. To achieve this, we performed a comprehensive systematic literature review of available evidence and, to the extent data allowed, extrapolated the comparative risks of $\mathrm{MOH}$ associated with available drug classes.

\section{Methods \\ Eligibility criteria}

Eligible studies could be either observational or clinical (randomized or non-randomized) in nature. Only studies that included adults 18 years of age and older who were suffering from acute migraine were eligible. Eligible studies must have reported $\mathrm{MOH}$ by treatment class (i.e. analgesic, ergot, opioid, or triptan), and according to versions of ICHD-2 [1, 7-9].

\section{Search strategy}

In consultation with an academic medical librarian, we conducted a systematic search of the medical literature using MEDLINE, EMBASE, and the Cochrane Controlled Trials Register (from inception to March 24, 2014). The search strategy was sensitive and broad, consisting of the following: 'medication overuse headache' and 'migraine'. Conference abstracts provided through the EMBASE search were also reviewed to determine if there were relevant studies recently completed. Additionally, hand searches of the bibliographies of published systematic reviews and health technology assessments were performed. All searches were performed independently, in duplicate.

\section{Data extraction}

We extracted data on the total number of patients, the number of patients with $\mathrm{MOH}$ by treatment class (i.e. analgesics, ergots, opioids, and triptans), $\mathrm{MOH}$ diagnostic criteria, and the country/region of each study. These data were extracted from the baseline characteristics of the studies. Two reviewers independently extracted and recorded all data in a Microsoft Excel spreadsheet. All data extraction were then checked by a third reviewer.

\section{Materials}

Out of 443 abstracts reviewed, a total of 29 studies were eligible [10-39]. Additional file 1: Figure S1 shows the flow chart, and Additional file 1: Table S1 show the list of studies excluded following full-text review with accompanying reason for exclusion. Table 1 presents the characteristics of the included studies. All included studies had been published since the year 2004, when the ICHD-2 was first released. Eleven of the included studies adhered to the definition of $\mathrm{MOH}$ in version 1 of the ICHD-2, whereas 9 studies adhered to the revision put forward in 2005, and 9 studies adhered to the appendix put forward in 2006. No studies made use of ICHD-3, released in beta in 2013. All studies took place in Europe (1 in Denmark, 3 in France, 2 in Germany, 19 in Italy, 2 in Norway, 1 in Spain, and 1 in Sweden). Two studies were population based, the remaining were based out of a clinical setting (i.e., investigator headache centers, hospital departments of neurology, of headache and pain clinics).

In general, the included studies reported on use of treatment classes, but did not distinguish which individual agent or agents (e.g., sumatriptan or eletriptan for triptans) had been administered to patients. Thus, analysis by individual agents was not possible. However, since all eligible studies were published between 2006 and 2013, it is reasonable to assume that most patients receiving ergots received dihydroergotamine (DHE) and not the older ergotamine tartrate.

All studies reported $\mathrm{MOH}$ as prevalence estimates within included study population; no study reported $\mathrm{MOH}$ as an outcome. All included studies were either observational (prospective or retrospective), clinical cohorts, or population surveys.

\section{Data considerations}

As indicated in section 3.4, no trials or observational studies looking at multiple migraine interventions reported development of $\mathrm{MOH}$ as an outcome. For this reason, the comparison between interventions had to be based on studies reporting prevalence estimates of $\mathrm{MOH}$. While relatively few available studies were specifically designed to estimate prevalence, several still provided data on the proportion of patients using each of the interventions that had developed $\mathrm{MOH}$. For example, several survey studies reported in their baseline table the number and proportion of enrolled patients with $\mathrm{MOH}$. Other publications described the characteristics of migraine patients in one or more clinics, which included the number and proportion of patients with $\mathrm{MOH}$. To justify inclusion of studies not designed to estimate prevalence, we made the assumption that prevalence estimates were not confounded by the designs of these studies. We verified that the eligibility criteria in these studies did not include criteria related to $\mathrm{MOH}$. 
Table 1 Summary of study characteristics

\begin{tabular}{|c|c|c|c|c|c|c|c|c|}
\hline \multirow[t]{2}{*}{ Study } & \multirow[t]{2}{*}{ Country } & \multirow{2}{*}{$\begin{array}{l}\text { Diagnosis } \\
\text { classification }\end{array}$} & \multirow{2}{*}{$\begin{array}{l}\text { Study } \\
\text { setting }\end{array}$} & \multirow{2}{*}{$\begin{array}{l}\text { No. } \\
\text { patients }\end{array}$} & \multicolumn{4}{|c|}{ No. medication overuse headache } \\
\hline & & & & & Analgesics & Ergots & Opioids & Triptans \\
\hline Altieri et al. 2009 [11] & Italy & ICHD-2 [7] & Clinic & 27 & 11 & NR & NR & 4 \\
\hline Ayzenberg et al. 2008 [12] & Germany & ICHD-2 [7] & Clinic & 29 & 14 & NR & NR & 15 \\
\hline Biagianti et al. 2012 [13] & Italy & ICHD-2 Revised [8] & Clinic & 52 & 26 & NR & NR & 20 \\
\hline Boe et al. 2007 [14] & Norway & ICHD-2 Appendix [7] & Clinic & 100 & 20 & 1 & NR & 23 \\
\hline Coppola et al. 2010 [15] & Italy & ICHD-2 Appendix [7] & Clinic & 29 & 10 & NR & NR & 9 \\
\hline Cupini et al. 2009 [16] & Italy & ICHD-2 Appendix [7] & Clinic & 33 & NR & 1 & NR & 4 \\
\hline Di Lorenzo et al. 2009 [17] & Italy & ICHD-2 [7] & Clinic & 107 & 18 & NR & NR & 29 \\
\hline Donnet et al. 2009 [18] & France & ICHD-2 [7] & Population & 320 & 157 & 25 & 29 & 64 \\
\hline Dousset et al. 2013 [19] & France & ICHD-2 Appendix [7] & Clinic & 42 & 8 & 1 & 0 & 9 \\
\hline Galli et al. 2011 [20] & Italy & ICHD-2Appendix [7] & Clinic & 82 & 21 & 2 & 3 & 22 \\
\hline Gambini et al. 2013 [21] & Italy & ICHD-2 Revised [8] & Clinic & 63 & 33 & NR & NR & 21 \\
\hline Gomez-Beldarrain et al. 2011 [22] & Spain & ICHD-2Revised [8] & Clinic & 42 & 25 & NR & NR & 3 \\
\hline Hagen et al. 2009 [23] & Norway & ICHD-2 Appendix [7] & Clinic & 56 & 18 & NR & 14 & 17 \\
\hline Jonsson et al. 2011 [6] & Sweden & ICHD-2 Appendix [7] & Population & 799 & 517 & 7 & 33 & 66 \\
\hline Lorenzo et al. 2012 [24] & Italy & ICHD-2 Appendix [7] & Clinic & 43 & 17 & NR & NR & 8 \\
\hline Pageler et al. 2008 [25] & Germany & ICHD-2 [7] & Clinic & 20 & 1 & 3 & NR & 5 \\
\hline Perrotta et al. 2010 [26] & Italy & ICHD-2 [7] & Clinic & 31 & 11 & NR & NR & 19 \\
\hline Perrotta et al. 2012 [27] & Italy & ICHD-2 [7] & Clinic & 27 & 4 & NR & NR & 6 \\
\hline Radat et al. 2013 [28] & France & ICHD-2 [7] & Clinic & 17 & 2 & NR & 2 & 4 \\
\hline Rainero et al. 2006 [29] & Italy & ICHD-2 [7] & Clinic & 18 & NR & 2 & NR & 3 \\
\hline Relja et al. 2006 [30] & Italy & ICHD-2 [7] & Clinic & 101 & 38 & 9 & 0 & 12 \\
\hline Rossi et al. 2006 [31] & Italy & ICHD-2 Revised [8] & Clinic & 118 & 63 & 3 & NR & 24 \\
\hline Rossi et al. 2011 [32] & Italy & ICHD-2 Revised [8] & Clinic & 100 & 57 & 1 & NR & 23 \\
\hline Sances et al. 2010 [33] & Italy & ICHD2 Revised [8] & Clinic & 172 & 42 & 5 & 5 & 50 \\
\hline Sandrini et al. 2011 [34] & Italy & ICHD-2 Appendix [7] & Clinic & 56 & 23 & 2 & NR & 20 \\
\hline Terrazzino et al. 2010 [35] & Italy & ICHD-2 Revised [8] & Clinic & 227 & 79 & 2 & 1 & 32 \\
\hline Trucco et al. 2010 [36] & Italy & ICHD-2Revised [8] & Clinic & 70 & 18 & 0 & NR & 9 \\
\hline Valguarnera et al. 2010 [37] & Italy & ICHD2 [7] & Clinic & 95 & 20 & 2 & 2 & 30 \\
\hline Zeeberg et al. 2006 [38] & Denmark & ICHD2 Revised [8] & Clinic & 216 & 63 & 8 & 12 & 43 \\
\hline
\end{tabular}

Since the prevalence of $\mathrm{MOH}$ is highly correlated with the prevalence of drug dispensing, prevalence estimates do not provide a good basis for comparison of risk of $\mathrm{MOH}$ associated with the different interventions. For example, triptans are prescribed more frequently than ergots, and so we expect to see higher numbers of triptanrelated $\mathrm{MOH}$ occurrences than ergot-related $\mathrm{MOH}$ occurrences. To form a fair basis for comparisons of the relevant interventions, it is therefore also necessary to know the frequency of treatment use. These were estimated post-hoc by a systematic review of the literature, and were incorporated in the calculations of comparative risk of MOH. To this end, we systematically searched MEDLINE and EMBASE for population-based studies providing estimates of medication use prevalence for the countries/regions represented in the eligible $\mathrm{MOH}$ prevalence studies.
The prevalence of medication use for migraine was derived from 5 studies identified in our literature review (See Table 2) [23, 40-43]. Because the data on medication prevalence use was limited, some assumptions needed to be made. For all countries, the prevalence of opioid use among those with migraine was not available. The closest evidence of opioid use prevalence that we identified was a Swedish study including chronic headache patients. This study yielded an opioid use prevalence of $4.1 \%$. Since use of opioids is known to be low in Europe (which is where all included studies came from) and since we believed it reasonable to assume opioid use among chronic daily headache patients would likely be higher than opioid use among acute migraine patients, we assumed an opioid use prevalence of $2 \%$ for all included studies. 
Table 2 Prevalence of medication use for episodic migraine in Europe (column 2) and the applied adjustment factors in calculating $\mathrm{MOH}$ prevalence and risk ratios (columns 3-6)

\begin{tabular}{|c|c|c|c|c|c|}
\hline Country/Region & Drug class (Prevalence, \%) & Analgesics & Ergotamines & Opioids & Triptans \\
\hline \multirow[t]{4}{*}{ Denmark [41] } & Analgesics (NA) & - & NA & NA & NA \\
\hline & Ergotamines (NA) & NA & - & NA & NA \\
\hline & Opioids (2.0) & NA & NA & - & $1: 13(0.08)$ \\
\hline & Triptans (26.0) & NA & NA & 13:1 (13.0) & - \\
\hline \multirow[t]{4}{*}{ France $[40,42]$} & Analgesics (12.0) & - & $4: 1(4.00)$ & $6: 1(6.0)$ & $6: 10(0.58)$ \\
\hline & Ergotamines (3.0) & $1: 4(0.25)$ & - & $3: 2(1.50)$ & $1: 7(0.14)$ \\
\hline & Opioids (2.0) & $1: 6(0.17)$ & $2: 3(0.67)$ & - & $1: 10(0.10)$ \\
\hline & Triptans (20.8) & 10:6 (1.73) & $7: 1(6.93)$ & 10:1 (10.4) & - \\
\hline \multirow[t]{4}{*}{ Germany $[40,42]$} & Analgesics (31.0) & - & $9: 2(4.43)$ & 15:1 (15.0) & $2: 1(2.14)$ \\
\hline & Ergotamines (7.0) & $2: 9(0.23)$ & - & $7: 2(3.50)$ & $1: 2(0.48)$ \\
\hline & Opioids (2.0) & 1:15 (0.06) & $2: 7(0.29)$ & - & $1: 7(0.14)$ \\
\hline & Triptans (14.5) & $1: 2(0.47)$ & 2:1 (2.07) & $7: 1(7.25)$ & - \\
\hline \multirow[t]{4}{*}{ Italy $[40,42]$} & Analgesics (12.0) & - & $12: 3(3.75)$ & $6: 1(6.00)$ & $4: 5(0.79)$ \\
\hline & Ergotamines (3.2) & $3: 12(0.27)$ & - & $8: 5(1.60)$ & $1: 5(0.21)$ \\
\hline & Opioids (2.0) & $1: 6(0.17)$ & $5: 8(0.63)$ & - & $1: 8(0.13)$ \\
\hline & Triptans (15.1) & $5: 4(1.25)$ & $5: 1(4.72)$ & $8: 1(7.55)$ & - \\
\hline \multirow[t]{4}{*}{ Norway [43] } & Analgesics (NA) & - & NA & NA & NA \\
\hline & Ergotamines (NA) & NA & - & NA & NA \\
\hline & Opioids (2.0) & NA & NA & - & $1: 19(0.05)$ \\
\hline & Triptans (37.0) & NA & NA & 19:1 (18.5) & - \\
\hline \multirow[t]{4}{*}{ Spain [40] } & Analgesics (16.4) & - & 4:5 (0.82) & $8: 1(8.20)$ & $1: 2(0.56)$ \\
\hline & Ergotamines (20.0) & $5: 4(1.22)$ & - & 10:1 (10.0) & $2: 3(0.69)$ \\
\hline & Opioids (2.0) & $1: 8(0.12)$ & $1: 10(0.10)$ & - & $1: 15(0.07)$ \\
\hline & Triptans (29.1) & 2:1 (1.77) & $3: 2(1.46)$ & 15:1 (14.6) & - \\
\hline \multirow[t]{4}{*}{ Sweden [23] } & Analgesics (NA) & - & NA & NA & NA \\
\hline & Ergotamines (NA) & NA & - & NA & NA \\
\hline & Opioids (2.0) & NA & NA & - & $3: 19(0.16)$ \\
\hline & Triptans (26.0) & NA & NA & $19: 3(6.34)$ & - \\
\hline
\end{tabular}

The medication use prevalence estimates presented in parenthesis next to treatment classes in column 2 are taken from included prevalence literature. The ratios (e.g. 3:1) presented in columns 3-6 are approximate ratios of prevalence of use of one medication over another. These ratios are also the adjustments factors multiplied to the unadjusted ratios of $\mathrm{MOH}$ for each study to account for the missing information about patients at risk on each medication within each study

\section{Analysis}

For each study we first calculated the proportion of patients with $\mathrm{MOH}$ in each treatment class, using the total number of patients as the denominator for both proportions. Subsequently the relative risk was calculated between each pair of treatment classes. As mentioned in the previous section, these relative risks are highly driven by the proportion of patients that received each treatment. For this reason, we applied an adjustment to the relative risk estimates. In particular, we first estimated the ratio with which treatments are being prescribed in clinical practice from prevalence estimates of medication use, and multiplied the inverse of this ratio to the above-obtained relative risks (see Table 2). Further, sensitivity analysis assuming an $8 \%$ medication use prevalence for opioids, was conducted.
The adjusted study relative risks were pooled for each comparison in a fixed-effect meta-analysis. A fixed-effect model was used to provide a fair weighted average of studies. The meta function in R.v.3.0 was used to pool results and produce forest plots. While this function by convention produces $95 \%$ credible intervals, one should only focus on the relative risk estimates and the weighted (pooled) average relative risk, since confidence intervals address sampling error and therefore are not valid under the above adjustments.

\section{Results}

Triptans versus analgesics

Twenty-five studies informed $\mathrm{MOH}$ for both triptans and analgesics in countries where medication use prevalence 
estimates were also available for both. Adjusted relative risks from these studies are presented in Fig. 1a. Fourteen studies yielded relative risks in favor of triptans, with adjusted relative risks varying from 0.12 to 0.94 . In 9 of these 14 studies the relative risk was statistically significant. Eleven studies yielded adjusted relative risks in favor of analgesics, with adjusted relative risk estimates varying from 1.05 to 5.00 . The fixed-effect weighted average adjusted relative risk was 0.65 , thus suggesting an average $35 \%$ relative risk reduction of $\mathrm{MOH}$ associated with triptans compared with analgesics.

\section{Triptans versus ergots}

Fourteen studies informed $\mathrm{MOH}$ for both triptans and ergots in countries where medication use prevalence estimates were also available for both. Adjusted relative risks from these studies are presented in Fig.1b. Four studies yielded adjusted relative risk estimates in favor of triptans, two yielded no difference (i.e. relative risk of 1.00), and eight studies yielded adjusted relative risk estimates in favor of ergots. The fixed-effect weighted average relative risk was 1.07 .

\section{Triptans versus opioids}

Eleven studies informed $\mathrm{MOH}$ for both triptans and opioids in countries where medication use prevalence estimates were also available for both. Adjusted relative risks from these studies are presented in Fig.1c. Five studies yielded adjusted relative risk estimates in favor of triptans, one study suggested no difference, and five studies yielded relative risk estimates in favor of opioids. The fixed-effect weighted average adjusted relative risk was 0.35 , suggesting an average $65 \%$ relative risk reduction of $\mathrm{MOH}$ with triptans compared with opioids.

\section{Ergots versus analgesics}

Twelve studies informed $\mathrm{MOH}$ for both ergots and analgesics in countries where medication use prevalence estimates were also available for both. Adjusted relative risks from these studies are presented in Fig.2a. Eleven of these yielded adjusted relative risk estimates in favor of ergots, and only one small study cell with a zero cell in the analgesics arm yielded a relative risk estimate in favor of analgesics. Among the former 11, adjusted relative risks varied between 0.07 and 0.90 . The fixed-effect weighted average adjusted relative risk was 0.41 , suggesting an average $59 \%$ relative risk reduction of $\mathrm{MOH}$ with ergots compared with analgesics.

\section{Ergots versus opioids}

Seven studies informed $\mathrm{MOH}$ for both ergots amines and opioids. Adjusted relative risks from these studies are presented in Fig.2b. Four of these studies yielded adjusted relative risk estimates in favor of ergots (ranging from 0.33 to 0.60 ), one yielded an adjusted relative risk estimate of 1.00 (i.e., no difference), and two studies, both with zero cells in the opioids arm, yielded relative risk estimates in favor of opioids. The fixed-effect weighted average relative risk was 0.76 , suggesting an average $24 \%$ relative risk reduction of $\mathrm{MOH}$ with ergots compared with opioids. As noted, this likely reflects mostly DHE use rather than ergotamine tartrate.

\section{Analgesics versus Opioids}

Nine studies informed $\mathrm{MOH}$ for both analgesics and opioids. Adjusted relative risks from these studies are presented in Fig.2c. Three studies yielded adjusted relative risk estimates in favor of analgesics, and six studies yielded relative adjusted risk estimates in favor of opioids. The fixed-effect weighted average adjusted relative risk was 1.09 , suggesting an average $9 \%$ increased risk of $\mathrm{MOH}$ with analgesics compared with opioids.

\section{Discussion}

Our analysis aimed to evaluate rates of $\mathrm{MOH}$ depending on the type of medication used. We found a considerably higher rate of $\mathrm{MOH}$ associated with analgesics in comparison to triptans and ergots. Our findings also suggest that opioids are either associated with a higher or similar risk of $\mathrm{MOH}$ compared to triptans and ergots, but evidence was more limited for these comparisons. These findings should be of interest to patients, clinicians, and policy-makers as many patients may self-medicate, and the magnitude of analgesic use is potentially higher than what has generally been observed in population-based studies.

There are strengths and limitations to our analysis that should be considered. Strengths of this study include our extensive searching to complete the largest and first systematic review of $\mathrm{MOH}$ associated with migraine pharmacotherapies. We used an approach that integrated evidence on medication overuse and medication use, the first such effort of which we are aware.

The employed approach further strengthens comparisons between interventions, since all studies provide data on at least two interventions, and so allows for the analysis to retain within-study validity. Studies included had to use the ICHD-2 criteria or later, and thus removed most uncertainty about the appropriateness of the $\mathrm{MOH}$ definition, which was particularly variable in older studies. However, this eligibility criterion also came with the limitation that the American Migraine Prevalence and Prevention (AMPP) study was not eligible [35]. In fact, no US studies were eligible under the employed criteria. Therefore, generalizability of our findings to the US population is somewhat limited.

We relied instead on observational studies reporting a mix of pseudo-risk data and medication use data to approximate the relative risk between interventions. 
(A)

Risk Ratio

Study

Altieri et al 2009

Ayzenberg et al 2008

Biagianti et al 2012b

Boe et al 2007

Coppola et al 2010

Di Lorenzo et al 2009

Donnet et al 2009

Dousset et al 2013

Galli et al 2011

Gambini et al 2013

Gomez-Beldarrain et al 2011

Hagen et al 2009

Lorenzo et al 2012

Pageler et al 2008

Perrotta et al 2010

Perrotta et al 2012

Radat et al 2013

Relja et al 2006

Rossi et al 2006

Rossi et al 2011

Sances et al $2010 \mathrm{~b}$

Sandrini et al 2011

Terrazzino et al 2010

Trucco et al 2010

Valguarnera et al 2010

Fixed effect model

Heterogeneity: $\boldsymbol{r}$-squared $=80.4 \%$,

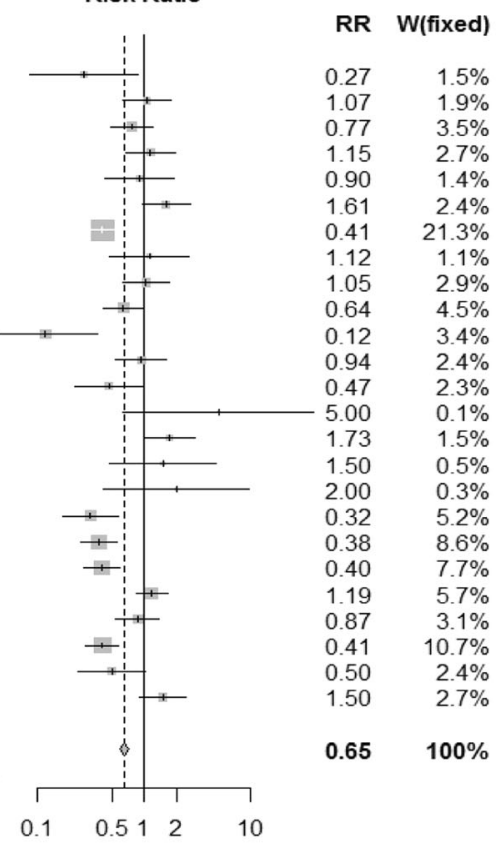

Study

Cupini et al 2009

Donnet et al 2009

Dousset et al 2013

Galli et al 2011

Pageler et al 2008

Relja et al 2006

Rossi et al 2006

Rossi et al 2011

Sances et al 2010b

Sandrini et al 2011

Terrazzino et al 2010

Trucco et al 2010

Valguarnera et al 2010

Fixed effect model

Heterogeneity: -squared $=\mathbf{4 3 . 1} \%$
Rainero et al 2006

(B)

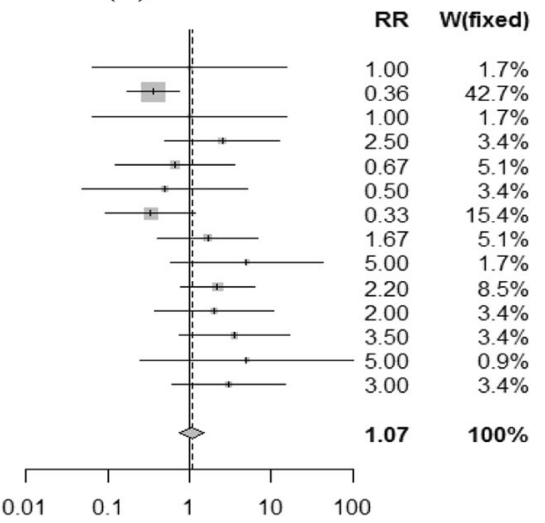

Study

Donnet et al 2009

Dousset et al 2013

Galli et al 2011

Hagen et al 2009

Jonsson et al 2011

Radat et al 2013

Relja et al 2006

Sances et al 2010b

Terrazzino et al 2010

Valguarnera et al 2010

Zeeberg et al 2006

Fixed effect model

Heterogeneity: 1 -squared $=67.3 \%$
(C)

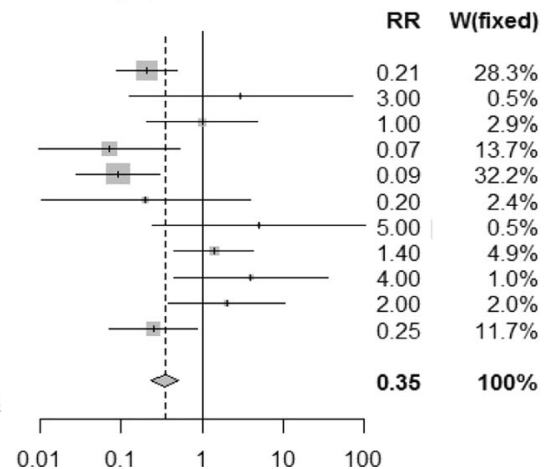

Fig. 1 Forest plots and weighted average estimate for the relative risk of $\mathrm{MOH}$ for the three comparisons: a triptans versus analgesics; $\mathbf{b}$ triptans versus ergots; and c triptans versus opioids 
(A)

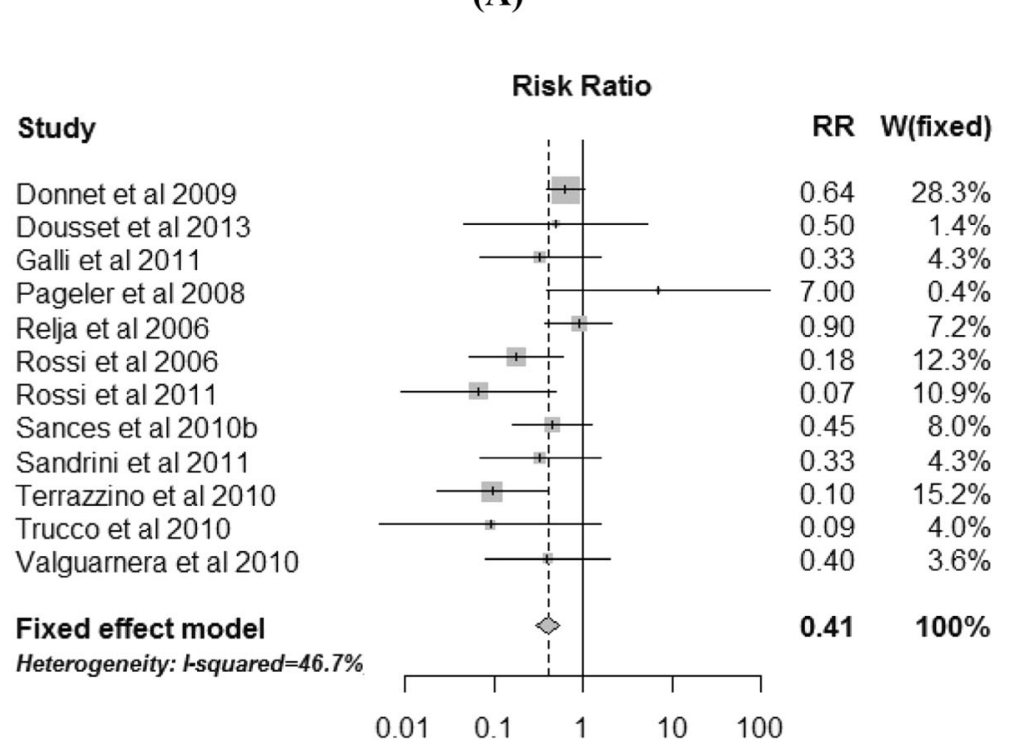

(B)

Study

Donnet et al 2009

Dousset et al 2013

Galli et al 2011

Relja et al 2006

Sances et al 2010b

Terrazzino et al 2010

Valguarnera et al 2010

Fixed effect model Heterogeneity: $l$-squared $=0.5 \%$

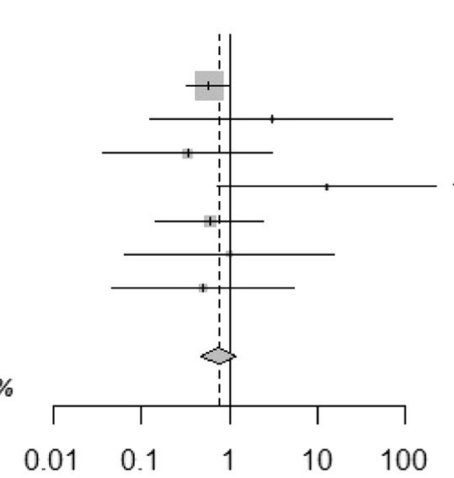

(C)

\section{Study}

Donnet et al 2009

Dousset et al 2013

Galli et al 2011

Hagen et al 2009

Radat et al 2013

Relja et al 2006

Sances et al $2010 \mathrm{~b}$

Terrazzino et al 2010

Valguarnera et al 2010

Fixed effect model

Heterogeneity: 1 -squared $=56.5 \%$

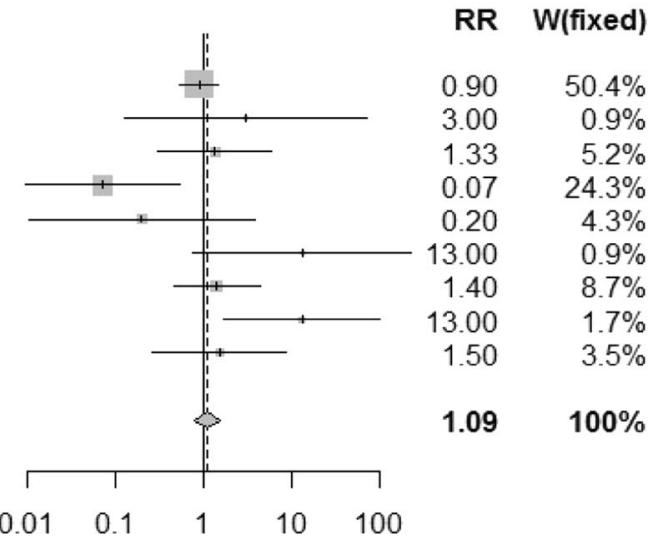

Fig. 2 Forest plots and weighted average estimate for the relative risk of $\mathrm{MOH}$ for the three comparisons: a ergots versus analgesics; $\mathbf{b}$ ergots versus opioids; and $\mathbf{c}$ analgesics versus opioids
RR W(fixed)

$0.59 \quad 70.7 \%$

$3.00 \quad 1.2 \%$

$0.33 \quad 7.3 \%$

$1.00 \%$

$0.60 \quad 12.2 \%$

$1.00 \quad 2.4 \%$

$0.50 \quad 4.9 \%$

$0.76 \quad 100 \%$ 
The analytical approached employed to synthesize results from these data relied on assumption that are arguably strong. There may therefore be controversy as to where the evidence fits in the evidence hierarchy. Recognizing the challenges of conducting these evaluations, and given the consistency of our study findings, the investigators believe this systematic review of observational studies provides strong inferences about the causative factors of $\mathrm{MOH}$. The heterogeneity between studies was generally low, in spite of the observational nature of the included studies and the additional uncertainty one might expect from the employed medication use prevalence adjustments. Also, the findings of the individual pair-wise meta-analysis added up 'indirectly'. For example, the direct comparison of triptans and ergots showed similar risk of $\mathrm{MOH}$, and both drug classes had similar relative risk estimates when compared with analgesics (0.65 and 0.41). These consistencies thus add considerable confidence to the findings of the analyses.

There are several possible reasons for our finding increased $\mathrm{MOH}$ associated with analgesic and opioid use and less so with triptans and ergots. Analgesics and opioids typically work via targeting pain receptors. On the other hand, both triptans and ergots share serotonergic agonist activity and are vasoconstrictors. Furthermore, analgesics are frequently used in an over-the-counter manner whereby patients self-administer and may do so without the supervision of a clinician. Triptans are, for the most part, prescription medications, and overuse may be better monitored than analgesics. In those countries in which triptans are available without a prescription (e.g. UK, Germany), quantity limits may prevent tendency to overuse.

While our findings are in line with current clinical guidelines and prejudice in favor of targeted migrainespecific pharmacotherapy, they should still only be interpreted as exploratory due to their observational nature. Further, the inclusion of only European studies limits our ability to extrapolate the findings to other global regions.

In summary, our study suggests that in patients with acute episodic migraine, the rate of $\mathrm{MOH}$ associated with analgesics and opioids is considerably higher than the rate of $\mathrm{MOH}$ associated with triptans and ergots. These findings should be of interest to patients, clinicians, and policymakers, as many patients self-medicate, and the magnitude of analgesic use is potentially higher than what has generally been observed in population-based studies.

\section{Additional file}

Additional file 1: Figure S1. Flow diagram for study selection. Table S1 List of studies excluded after full text review and accompanying reason for exclusion. (DOCX $113 \mathrm{~kb}$ )

\section{Authors' contributions}

$\mathrm{KT}$ prepared the first draft of the manuscript and contributed to all revisions, contributed to the concept and study design, contributed to the systematic literature review, contributed to the statistical analyses, and contributed to the interpretation of findings. CSE contributed to the writing of the manuscript, the concept and study design, the systematic literature review, as well as the interpretation of findings. ED and SE contributed to the concept and study design, systematic literature review, and the writing of the manuscript. SK contributed to concept and study design, the statistical analysis and the writing of the manuscript. RB and ER contributed to the concept and study design, the writing of the manuscript and the interpretation of findings. EJM, MLM, and ST, contributed to the concept and study design, the writing of the manuscript, the systematic literature review, and the interpretation of findings. All authors read and approved the final manuscript.

\section{Competing interests}

The study was funded by Pfizer Inc. Redwood Outcomes conducted this study. Drs. Thorlund and Mills are founding partners of Redwood Outcomes and were paid consultants for conducting this study and for the development of this manuscript. Drs. Thorlund and Mills have previously consulted to Boehringer Ingleheim, Merck, Pfizer, Novartis, Janssen, Roche, Novo Nordisk, UCB, Sanofi, BTG, Bayer, Teva, Lundbeck, Lilly, and Gilead on systematic reviews and network meta-analysis. In addition, Drs. Thorlund and Mills have received grant funding from the Canadian Institutes of Health Research (CIHR) Drug Safety \& Effectiveness Network to develop methods and educational materials on network meta-analysis. Eric Druyts, and Ping Wu are employees of Redwood Outcomes. Drs Bhambri and Ramos are full-time employees of Pfizer Inc. Dr. Lanteri-Milnet has received compensation from Allergan, Almirall SAS, Amgen, Astellas, AstraZeneca Pharmaceuticals, ATI, BMS, Boehringer, Boston Scientific, CoLucid, Convergence, Glaxo-SmithKline, Grunenthal, Lilly, Johnson \& Johnson, Medtronic, Menarini, MSD, Pierre Fabre, Pfizer, ReckittBenckiser, Saint-Jude, Sanofi-Aventis, UCB, Zambon. Dr. Sun-Edelstein has received lecture fees from Pfizer and MSD. Dr. Tepper has received grant funding from Alder, Allergan, Amgen, ATI, ElectroCore, eNeura, GSK, Teva, Pernix, Optinose/Avanir/Otsuka; served as a consultant to Acorda, Allergan, Amgen, ATI, Avanir, Depomed, Impax, Pfizer, Scion Neurostim, Teva, Zosana; participated in speakers bureau activities for Allergan, Depomed, Impax, Pernix, Teva and Advisory activities for Allergan, Amgen, ATI, Avanir, Dr. Reddy's, Merck, Teva, Pfizer. Dr. Tepper further holds stock in ATI. Drs. Ebrahim and Kanters have nothing to disclose.

\section{Author details}

'Department of Clinical Epidemiology \& Biostatistics, McMaster University, Hamilton, ON, Canada. ${ }^{2}$ Redwood Outcomes, 302-1505 2nd Ave. West, Vancouver, BC, Canada. ${ }^{3}$ Department of Medicine, St. Vincent's Hospital, The University of Melbourne, Melbourne, Australia. ${ }^{4}$ Department of Medicine, Faculty of Medicine, University of British Columbia, Vancouver, BC, Canada. ${ }^{5}$ School of Population and Public Health, Faculty of Medicine, University of British Columbia, Vancouver, BC, Canada. ${ }^{6}$ Pfizer Ltd, New York, NY, USA.

${ }^{7}$ Pain Department, CHU Nice, France - FHU InovPain, Université Nice Côte d'Azur, Nice, France. ${ }^{8}$ Geisel School of Medicine at Dartmouth, Hanover, NH, USA. ${ }^{9}$ INSERM U1 107, Neuo-Dol, Trigeminal Pain and Migraine Université Auvergne, Clermont-Ferrand, France.

Received: 22 July 2016 Accepted: 22 October 2016

Published online: 24 November 2016

\section{References}

1. Headache Classification Committee of the International Headache Society (IHS). The International Classification of Headache Disorders, 3rd edition (beta version). Cephalalgia. 2013;33:629-808.

2. De Felice M, Ossipov MH, Porreca F (2011) Update on medication-overuse headache. Curr Pain Headache Rep 15:79-83

3. Russell MB, Lundqvist C (2012) Prevention and management of medication overuse headache. Curr Opin Neurol 25:290-5

4. Grande RB, Aaseth K, Gulbrandsen P, Lundqvist C, Russell MB (2008) Prevalence of primary chronic headache in a population-based sample of 30- to 44-year-old persons. The Akershus study of chronic headache. Neuroepidemiology 30:76-83

5. Aaseth K, Grande RB, Kvaerner KJ, Gulbrandsen P, Lundqvist C, Russell MB (2008) Prevalence of secondary chronic headaches in a population-based 
sample of 30-44-year-old persons. The Akershus study of chronic headache. Cephalalgia 28:705-13

6. Jensen R, Stovner $L J$ (2008) Epidemiology and comorbidity of headache. Lancet Neurol 7:354-61

7. Headache Classification Committee of The International Headache Society (2004) The International Classification of Headache Disorders, 2nd edition. Cephalalgia 24:1-160

8. Silberstein S, Olesen J, Bousser M (2005) The International Classification of Headache Disorders, 2nd edition (ICHD-II)-revision of criteria for 8.2 Medication-overuse headache. Cephalagia 25:460-465

9. Olesen J, Bousser M, Diener H (2006) New appendix criteria open for a broader concept of chronic migraine. Cephalagia 26:742-746

10. Altieri M, Di Giambattista R, Di Clemente L, Fagiolo D, Tarolla E, Mercurio A, Vicenzini E, Tarsitani L, Lenzi GL, Biondi M, Di Piero V (2009) Combined pharmacological and short-term psychodynamic psychotherapy for probable medication overuse headache: a pilot study. Cephalalgia 29:293-9

11. Ayzenberg I, Oberman M, Leineweber K, Franke L, Yoon MS, Diener HC, Katsarava Z (2008) Increased activity of serotonin uptake in platelets in medication overuse headache following regular intake of analgesics and triptans. J Headache Pain 9:109-112

12. Biagianti B, Grazzi L, Gambini O, Usai S, Muffatti R, Scarone S, Bussone G (2012) Decision-making deficit in chronic migraine patients with medication overuse. Neurol Sci 33(Suppl 1):S151-5

13. Boe MG, Mygland A, Salvesen R (2007) Prednisolone does not reduce withdrawal headache: a randomized, double-blind study. Neurology 69:26-31

14. Coppola G, Curra A, Di Lorenzo C, Parisi V, Gorini M, Sava SL, Schoenen J, Pierelli F (2010) Abnormal cortical responses to somatosensory stimulation in medication-overuse headache. BMC Neurol 10:126

15. Cupini LM, De Murtas M, Costa C, Mancini M, Eusebi P, Sarchielli P, Calabresi P (2009) Obsessive-compulsive disorder and migraine with medicationoveruse headache. Headache 49:1005-13

16. Di Lorenzo C, Di Lorenzo G, Sances G, Ghiotto N, Guaschino E, Grieco GS, Santorelli FM, Casali C, Troisi A, Siracusano A, Pierelli F (2009) Drug consumption in medication overuse headache is influenced by brain-derived neurotrophic factor Val66Met polymorphism. J Headache Pain 10:349-55

17. Donnet A, Lanteri-Minet M, Aucoin F, Allaf B (2009) Use and overuse of antimigraine drugs by pharmacy personnel in France: COTA survey: Research submission. Headache 49:1014-1021

18. Dousset V, Maud M, Legoff M, Radat F, Brochet B, Dartigues JF, Kurth T (2013) Probable medications overuse headaches: validation of a brief easy-to-use screening tool in a headache centre. J Headache Pain 14:81

19. Galli F, Pozzi G, Frustaci A, Allena M, Anastasi S, Chirumbolo A, Ghiotto N, Guidetti V, Matarrese A, Nappi G, Pazzi S, Quartesan R, Sances G, Tassorelli C (2011) Differences in the personality profile of medication-overuse headache sufferers and drug addict patients: a comparative study using MMPI-2. Headache 51:1212-27

20. Gambini O, Biagianti B, Grazzi L, Usai S, Scarone S, Bussone G (2013) Psychiatric screening for migraine patients. Neurol Sci 34(Suppl 1):S61-6

21. Gomez-Beldarrain M, Carrasco M, Bilbao A, Garcia-Monco JC (2011) Orbitofrontal dysfunction predicts poor prognosis in chronic migraine with medication overuse. J Headache Pain 12:459-66

22. Hagen K, Albretsen C, Vilming ST, Salvesen R, Gronning M, Helde G, Gravdahl G, Zwart JA, Stovner LJ (2009) Management of medication overuse headache: 1-year randomized multicentre open-label trial. Cephalalgia 29:221-32

23. Jonsson P, Hedenrud T, Linde M (2011) Epidemiology of medication overuse headache in the general Swedish population. Cephalalgia 31:1015-22

24. Lorenzo CD, Coppola G, Curra A, Grieco G, Santorelli FM, Lepre C, Porretta E, Pascale E, Pierelli F (2012) Cortical response to somatosensory stimulation in medication overuse headache patients is influenced by angiotensin converting enzyme (ACE) I/D genetic polymorphism. Cephalalgia 32:1189-97

25. Pageler L, Katsarava Z, Diener HC, Limmroth V (2008) Prednisone vs. placebo in withdrawal therapy following medication overuse headache. Cephalalgia 28:152-6

26. Perrotta A, Arce-Leal N, Tassorelli C, Gasperi V, Sances G, Blandini F, Serrao M, Bolla M, Pierelli F, Nappi G, Maccarrone M, Sandrini G (2012) Acute reduction of anandamide-hydrolase (FAAH) activity is coupled with a reduction of nociceptive pathways facilitation in medication-overuse headache subjects after withdrawal treatment. Headache 52:1350-61

27. Perrotta A, Serrao M, Sandrini G, Burstein R, Sances G, Rossi P, Bartolo M, Pierell F, Nappi G (2010) Sensitisation of spinal cord pain processing in medication overuse headache involves supraspinal pain control. Cephalalgia 30:272-84
28. Radat F, Chanraud S, Di Scala G, Dousset V, Allard M (2013) Psychological and neuropsychological correlates of dependence-related behaviour in Medication Overuse Headaches: a one year follow-up study. J Headache Pain 14:59

29. Rainero I, Ferrero M, Rubino E, Valfre W, Pellegrino M, Arvat E, Giordano R, Ghigo E, Limone P, Pinessi L (2006) Endocrine function is altered in chronic migraine patients with medication-overuse. Headache 46:597-603

30. Relja G, Granato A, Bratina A, Antonello RM, Zorzon M (2006) Outcome of medication overuse headache after abrupt in-patient withdrawal. Cephalalgia 26:589-95

31. Rossi P, Di Lorenzo C, Faroni J, Cesarino F, Nappi G (2006) Advice alone vs. structured detoxification programmes for medication overuse headache: a prospective, randomized, open-label trial in transformed migraine patients with low medical needs. Cephalalgia 26:1097-105

32. Rossi P, Faroni JV, Nappi G (2011) Short-term effectiveness of simple advice as a withdrawal strategy in simple and complicated medication overuse headache. Eur J Neurol 18:396-401

33. Sances G, Ghiotto N, Galli F, Guaschino E, Rezzani C, Guidetti V, Nappi G (2010) Risk factors in medication-overuse headache: a 1-year follow-up study (care II protocol). Cephalalgia 30:329-36

34. Sandrini G, Perrotta A, Tassorelli C, Torelli P, Brighina F, Sances G, Nappi G (2011) Botulinum toxin type-A in the prophylactic treatment of medicationoveruse headache: a multicenter, double-blind, randomized, placebocontrolled, parallel group study. J Headache Pain 12:427-33

35. Silberstein S, Loder E, Diamond S, Reed ML, Bigal ME, Lipton RB, Group AA (2007) Probable migraine in the United States: results of the American Migraine Prevalence and Prevention (AMPP) study. Cephalalgia 27:220-9

36. Terrazzino S, Sances G, Balsamo F, Viana M, Monaco F, Bellomo G, Martignoni E, Tassorelli C, Nappi G, Canonico PL, Genazzani AA (2010) Role of 2 common variants of 5 HT2A gene in medication overuse headache. Headache 50:1587-96

37. Trucco M, Meineri P, Ruiz L, Gionco M (2010) Medication overuse headache: withdrawal and prophylactic therapeutic regimen. Headache 50:989-97

38. Valguarnera F, Tanganelli P (2010) The efficacy of withdrawal therapy in subjects with chronic daily headache and medication overuse following prophylaxis with topiramate and amitriptyline. Neurol Sci 31(Suppl 1):S175-7

39. Zeeberg P, Olesen J, Jensen R (2006) Probable medication-overuse headache: the effect of a 2-month drug-free period. Neurology 66:1894-8

40. Bloudek LM, Stokes M, Buse DC, Wilcox TK, Lipton RB, Goadsby PJ, Varon SF, Blumenfeld AM, Katsarava Z, Pascual J, Lanteri-Minet M, Cortelli P, Martelletti P (2012) Cost of healthcare for patients with migraine in five European countries: results from the International Burden of Migraine Study (BBMS). J Headache Pain 13:361-78

41. Lyngberg AC, Rasmussen BK, Jorgensen T, Jensen R (2005) Secular changes in health care utilization and work absence for migraine and tension-type headache: a population based study. Eur J Epidemiol 20:1007-14

42. MacGregor EA, Brandes J, Eikermann A (2003) Migraine prevalence and treatment patterns: the global Migraine and Zolmitriptan Evaluation survey. Headache 43:19-26

43. Zwart JA, Dyb G, Hagen K, Svebak S, Holmen J (2003) Analgesic use: a predictor of chronic pain and medication overuse headache: the Head-HUNT Study. Neurology 61:160-4

\section{Submit your manuscript to a SpringerOpen ${ }^{\circ}$ journal and benefit from:}

- Convenient online submission

- Rigorous peer review

- Immediate publication on acceptance

- Open access: articles freely available online

- High visibility within the field

- Retaining the copyright to your article

Submit your next manuscript at springeropen.com 